\title{
E्己̌reAáo O Centro de Ciências da Educação da UFSC: relatos de uma trajetória
}

\author{
Leda Scheibe ${ }^{1, \|}$ \\ Vera Lúcia Bazzo"
}

'Universidade do Oeste de Santa Catarina (UNOESC), Joaçaba/SC - Brasil "Universidade Federal de Santa Catarina (UFSC), Florianópolis/SC - Brasil

RESUMO - O Centro de Ciências da Educação da UFSC: relatos de uma trajetória. Este artigo descreve parte da história do Centro de Ciências da Educação da Universidade Federal de Santa Catarina - CED/UFSC, numa tentativa de revelar seu papel na formação de professores. Inscreve-se, portanto, no campo de estudos da História da Educação. Discute a função das primeiras escolas normais, referindo-se à criação da Escola Normal Catharinense e da Faculdade Catarinense de Filosofia, relacionando-as com a posterior fundação da Universidade Federal de Santa Catarina. Comenta o desenvolvimento do CED/UFSC ao longo dos últimos cinquenta anos, afirmando-o como o principal locus de formação de quadros para a educação no Estado de Santa Catarina.

Palavras-chave: História da Educação. Formação de Professores. Centro de Educação.

ABSTRACT - The Center for Education Sciences of UFSC: accounts of a trajectory. This article describes some of the history of the Center for Education Sciences at Universidade Federal de Santa Catarina (CED/UFSC), in an attempt to reveal its role in teacher training. It is thus inscribed in the history of education field. The paper discusses the function of the first normal schools, as teacher's colleges were known, referring to the creation of the Escola Normal Catharinense and the Faculdade Catarinense de Filosofia [The Santa Catarina College of Philosophy], and their relation with the later founding of Universidade Federal de Santa Catarina. It comments on the development of the Center for Education Sciences over the past fifty years, affirming its role as the main locus for the training of education professionals in Santa Catarina state.

Keywords: History of Education. Teacher Training. Education Center.

Educação \& Realidade, Porto Alegre, v. 41, n. especial, p. 1507-1522, dez. 2016. 1507 http://dx.doi.org/10.1590/2175-623668721 


\section{Introdução}

O presente trabalho, além de sua importância no resgate do itinerário de uma das mais antigas instituições formadoras de professores do Estado de Santa Catarina - o hoje denominado Centro de Ciências da Educação CED/UFSC - tenta responder ao desafio que nos faz a Revista Educação e Realidade/FACED/UFRGS, em sua edição comemorativa dos 45 anos de existência de sua Faculdade de Educação, qual seja, a de escrever sobre o papel dessas instituições na formação docente, procurando conferir um sentido histórico às suas memórias e respectivas trajetórias.

Este artigo, portanto, propõe-se a explicitar, ainda que de maneira sintética e pontual, um pouco da história da formação de professores realizada no Estado de Santa Catarina, e, particularmente, o papel da Universidade Federal de Santa Catarina - UFSC, nesse processo, tarefa a que nos dispusemos com o prazer de quem, de certa forma, foi também protagonista dessa jornada.

\section{Antecedentes Históricos: a Escola Normal Catharinense}

Como nas demais regiões do país, a instituição que formava os quadros docentes para as escolas públicas até o final de século XIX era a Escola Normal, cuja criação e manutenção, durante o período imperial, era de responsabilidade da província, e, posteriormente, com o advento da república, dos respectivos estados.

A primeira Escola Normal da qual se tem notícia em Santa Catarina foi criada em 1880. Esta instituição, porém, não manteve um funcionamento regular, datando, então, do início do período republicano, 1892, a criação da Escola Normal Catharinense, localizada em Florianópolis, que, de forma mais efetiva, dedicou-se à formação de professores (Scheibe; Daniel, 2002).

O advento da república, entretanto, não trouxe alterações significativas imediatas para a instrução pública no país. O federalismo descentralizado, o Estado oligárquico, subordinado aos interesses dos grupos dominantes das regiões produtoras e exportadoras de café, o quadro social, político e econômico da chamada Primeira República produzia grandes discrepâncias no desenvolvimento dos estados e, portanto, na organização do seu ensino. Não surpreende, pois, que o Estado de São Paulo tenha sido paradigmático no campo educacional brasileiro nas primeiras décadas desse período, quando comissões de outros estados para lá se dirigiam com o intuito de estudar a organização do serviço de instrução pública, ao mesmo tempo em que missões de professores paulistas eram solicitadas a vir aos diversos estados para auxiliar na reorganização de seus respectivos sistemas de ensino (Scheibe, 2004).

Em razão desse contexto, na segunda década do século XX, a figura mais proeminente na organização do ensino em Santa Catarina 
foi o professor Orestes Guimarães, formado na Escola Normal da Praça da República de São Paulo. Nomeado Inspetor Geral de Ensino, ocupou este cargo durante vários anos, assessorando a instrução pública e a reorganização dos cursos normais, seguindo as linhas básicas da instrução pública paulista.

Até a criação da Faculdade Catarinense de Filosofia, na década de 1950, portanto, não se contava aqui no estado com formação de professores para a escola secundária, em nível superior. Configurava-se, à época, uma dualidade institucional na formação docente pela existência, desde a década de 1930, de duas modalidades de ensino normal, as Escolas Normais Secundárias e as Escolas Normais Primárias. Esta dualidade já vinha ocorrendo em São Paulo, onde os então denominados cursos complementares haviam sido criados para dar sequência ao ensino primário, passando a ser também uma forma adicional de preparar professores para as séries iniciais de escolaridade, medida justificada como necessária para expandir o sistema de formação docente e prover o ensino primário de pessoal habilitado.

Esta forma de organização foi depois sancionada pela Lei Orgânica do Ensino Normal (Brasil, 1946a), assinada logo após o final do Estado Novo, quando as Leis Orgânicas de Ensino - decretos-leis federais promulgados de 1942 a $1946^{1}$ - pretenderam suprir a ausência de normas centrais e delinear um processo de regulamentação em âmbito federal. A referida lei regulamentou a divisão do ensino normal em dois ciclos: i) escolas normais de primeiro ciclo, também denominadas regionais, que formavam regentes para o ensino primário (séries iniciais), em quatro anos de estudo, destinadas a alunos com idade mínima de 13 anos, portadores de certificados de educação primária de cinco anos de estudo; ii) o curso normal de segundo ciclo, que formava o professor primário em dois anos de estudos, cujo ingresso exigia o ginasial concluído. Este curso era ministrado nas escolas normais e nos institutos de educação, instituições que deveriam também ser responsáveis por outros cursos de especialização de professores, tais como educação especial, curso complementar primário, ensino supletivo, desenho e artes aplicadas, música e canto, e administração escolar (Tanuri, 2000).

A Escola Normal Catharinense, por ocasião da reforma de ensino no estado, ocorrida em 1935, transformou-se no Instituto de Educação de Florianópolis². Neste período, as grandes cidades brasileiras como São Paulo e Rio de Janeiro faziam das universidades recém-criadas o local que abrigava a intelectualidade num ambiente de pesquisa e docência, criando condições institucionais para a produção científica e cultural do país. Este papel foi aqui assumido pelo instituto, uma vez que ocorria semelhante movimento em torno desta instituição. O Instituto de Educação de Florianópolis, ao lado da Academia Catarinense de Letras, fundada em 1924, e do Instituto Histórico e Geográfico de Santa Catarina foram instituições significativas para o desenvolvimento da vida cultural e intelectual do estado.

Educação \& Realidade, Porto Alegre, v. 41, n. especial, p. 1507-1522, dez. 2016. 1509 
Neste instituto de educação, que abrigava o curso normal, os intelectuais, além de lecionarem, ocupavam-se também com o estudo, com a pesquisa e com a produção de publicações científicas. Neste afã, inclusive voltado à difusão do movimento escolanovista no estado nos anos de 1940, foi criada a revista Estudos Educacionais ${ }^{3}$, por João Roberto Moreira ${ }^{4}$. A revista realizava forte intercâmbio de ideias entre intelectuais catarinenses, nacionais e mesmo estrangeiros, dentre os quais Fernando de Azevedo, Lourenço Filho, Donald Pierson e Roger Bastide (Nascimento; Daniel, 2002). Este periódico veiculava as principais ideias e concepções educativas presentes nas aulas ministradas no Instituto.

O papel desempenhado pelo Instituto de Educação de Florianópolis e pelos intelectuais desse momento histórico em Santa Catarina, particularmente durante a década de 1940, foi determinante para propiciar as condições que levaram à criação da Faculdade de Filosofia Catarinense e, depois, das duas primeiras universidades públicas em Santa Catarina: Universidade Federal de Santa Catarina (UFSC) e Universidade do Estado de Santa Catarina (UDESC), ambas fundadas nos primeiros anos da década de 1960. Consequentemente, o Instituto de Educação de Florianópolis foi o embrião da institucionalização das unidades universitárias que se dedicaram à formação de professores e ao desenvolvimento das ciências da educação em nosso território (Scheibe; Bazzo, 2014).

Podemos dizer, então, que essas duas unidades universitárias foram, de certa forma, gestadas nesse rico espaço cultural que se desenvolveu no Instituto de Educação de Florianópolis, escola modelo para as demais escolas normais do estado, num período de institucionalização das ciências sociais no Brasil, em sintonia com o processo de desenvolvimento do campo de estudo educacional que então vinha ocorrendo (Daros, 2002).

\section{A Faculdade Catarinense de Filosofia: nasce em terras catarinenses a formação de professores em nível superior}

Na década de 1950, já visando à possibilidade futura de se ter uma universidade no estado, pela determinação de um grupo de intelectuais da época, entre os quais, o Professor Henrique da Silva Fontes ${ }^{5}$, foi criada a Faculdade Catarinense de Filosofia. Seu objetivo inicial, conforme palavras de seu fundador, era preparar pessoal qualificado para o magistério em Santa Catarina. Estranhamente, porém, o Curso de Pedagogia não viria inicialmente funcionar junto a ela. Somente em 1960, cinco anos depois de sua criação, foi lhe concedida autorização federal para a criação dos cursos de Pedagogia e de Didática, o que representou efetivamente o início das licenciaturas no estado de Santa Catarina (Scheibe; Daniel, 2002).

1510 Educação \& Realidade, Porto Alegre, v. 41, n. especial, p. 1507-1522, dez. 2016. 
Expressava-se, quem sabe, desde esses tempos, a dicotomia Licenciaturas-Pedagogia, que acompanha e talvez explique algumas das grandes dificuldades que as posteriores tentativas teóricas e políticas de superar o modelo chamado de três mais $u m^{6}$, tão nosso conhecido e de deletérias consequências à formação, enfrentaram. Foram ingentes os esforços dos educadores, organizados em suas entidades representativas, para a criação de políticas públicas que suportassem uma formação para o magistério capaz de articular teoria e prática de forma mais orgânica, na busca de uma base comum de formação, nas décadas que se sucederam.

Em função da criação dos cursos de Didática e de Pedagogia, e por força do Decreto-Lei no 9053 (Brasil, 1946b), que estabelecia a necessidade de manutenção de ginásios de aplicação nas Faculdades de Filosofia do país, a UFSC fundou, em 1961, o seu Ginásio de Aplicação, para servir de campo de estágio destinado à prática docente dos estudantes matriculados nos cursos de didática (geral e específica) da Faculdade Catarinense de Filosofia (FCF). Nasceu, portanto, antes da instalação do Centro de Educação, ao qual iria se vincular anos depois.

A criação do Ginásio de Aplicação foi solicitada em julho de 1959, a requerimento do então diretor da FCF, Professor Henrique da Silva Fontes, mas seu funcionamento, ainda condicional, só foi autorizado em março de 1961, por meio do Ato no 5 da Inspetoria Seccional de Florianópolis, órgão estadual do Ministério da Educação (MEC). Mesmo assim, apenas em julho do mesmo ano foi que recebeu a esperada confirmação para iniciar seus trabalhos. O MEC, então, ratificava o referido pedido, autorizando o funcionamento condicional do Ginásio de Aplicação pelo período de quatro anos. Desde aquele momento, a nova instituição escolar passa a integrar o Sistema Federal de Ensino (Neckel; Küchler, 2010).

Inicialmente, ofereceu-se somente a primeira série do curso ginasial. Sucessivamente, porém, foram sendo implantadas as séries seguintes. O número de suas classes permaneceu estável até 1967, quando foi obrigado a ampliar o seu atendimento devido ao aumento exponencial de estudantes estagiários que a ele acorriam vindo dos cursos de formação de professores da FCF. Foram, então, criadas três turmas para a $1^{\text {a }}$ série ginasial. O Ginásio de Aplicação não parou mais de crescer durante as duas décadas seguintes.

Em 1970 mudou de nome para Colégio de Aplicação (CA/UFSC) e passou a oferecer também as primeiras séries do chamado segundo ciclo, criando os cursos Clássico e Científico. Sua qualidade também crescia junto com o desenvolvimento das instituições federais de ensino e com as sucessivas mudanças na educação. Em 1980, a partir do aumento do número de cursos de licenciatura e das mudanças no currículo do curso de Pedagogia, impõe-se a criação do Ensino Fundamental no CA.

Educação \& Realidade, Porto Alegre, v. 41, n. especial, p. 1507-1522, dez. 2016. 1511 
Atualmente, organiza-se como uma grande unidade do Centro de Ciências da Educação (CED), funcionando como uma escola pública, que oferece ensino fundamental e médio à comunidade, a qual disputa suas vagas, concedidas via sorteio universal, com o fervor de quem sabe ser aquela escola o que de melhor poderiam oferecer às suas crianças e jovens.

É forte a ligação do CA com o CED/UFSC, pois, assim como a Universidade que o abriga, ele realiza atividades de ensino, pesquisa e extensão. É em suas dependências também que muitos dos estudantes da UFSC realizam seus múltiplos estágios, mas são as Licenciaturas, hoje mais de duas dezenas de cursos, as que mais se beneficiam da excelente qualidade de seu ensino, desenvolvendo ali, em respeitoso trabalho conjunto, a iniciação à docência e o difícil aprendizado da profissão de seus estudantes durante os estágios supervisionados (Perspectiva UFSC, 2015).

Também vinculado ao CED/UFSC, surgia, em 1980, por reivindicação das mães professoras e servidoras da UFSC, e com base na lei que as protegia nesse direito, o Núcleo de Desenvolvimento Infantil (NDI). Era responsável pela guarda e cuidado das crianças, funcionando como uma creche. Ao longo dos anos, porém, com o desenvolvimento dos estudos sobre a infância, e a consequente necessidade de formação de quadros para a Educação Infantil, agora já uma habilitação dos Cursos de Pedagogia, o NDI foi se transformando em um espaço importante do CED/UFSC a produzir conhecimento e oferecer oportunidades de estudos e ensino sobre a temática da infância.

Hoje, cada vez mais, constitui-se como campo de estágio e observação para diversos cursos da UFSC e de outras universidades do Estado de Santa Catarina. Envolve-se permanentemente em atividades de pesquisa, extensão e de formação continuada de professores das redes municipais e estadual, sendo, inclusive, referência de qualidade neste nível de educação no país e mesmo no exterior.

O Centro de Ciências da Educação, assim, além de seus próprios departamentos de ensino, articula-se a essas duas unidades formadoras em torno de suas lutas por uma educação pública e de qualidade em todos os níveis de escolaridade para todos, formando professores e pesquisadores que hoje povoam as redes e os sistemas de ensino catarinenses, propiciando-lhes competência e compromisso social.

\section{A Criação do CED/UFSC: alguns relatos de seus primeiros feitos}

O Centro de Ciências da Educação da Universidade Federal de Santa Catarina ${ }^{7}$ foi pensado no interior das discussões sobre a implantação na UFSC da Reforma Universitária imposta pelo Governo Militar por meio da Lei 5.540 (Brasil, 1968) iniciativa que acabou se concretizando pioneiramente no Brasil nesta universidade em 1970. Talvez por essa forte influência, a denominação desta unidade acadêmica não te- 
nha seguido a tradição da época, preferindo-se o conceito de Centro ao de Faculdade. O Centro de Educação - CED/UFSC surgiu, então, a partir da Faculdade de Filosofia, Ciências e Letras (FFCL), da qual foi desmembrado naquele período, em processo coordenado por aquele que viria ser seu primeiro diretor, o professor Nilson Paulo ${ }^{8}$, dando seguimento à estruturação da UFSC nos moldes preconizados pela Reforma Universitária em curso.

Em 1971, o CED/UFSC foi instalado oficialmente pela Portaria 270/71, do Magnífico Reitor, a qual constituía também seu primeiro Conselho Departamental. Sua proposta de composição inicial dizia que teria três departamentos assim denominados: Departamento de Metodologia de Ensino (MEN); Departamento de Estudos Especializados em Educação (EED) e Departamento de Fundamentos da Educação. Os dois primeiros foram pensados em relação aos componentes teórico-práticos da formação docente. O terceiro, que nunca chegou a ser efetivamente instalado, destinar-se-ia a reunir as disciplinas consideradas fundantes da teoria educacional, quais sejam: Filosofia da Educação, História da Educação, Psicologia da Educação, Sociologia da Educação, entre outras. Reuniria, dessa forma, o conjunto dos conteúdos voltados à reflexão teórica, isto é, aqueles fundamentos que formavam verdadeiramente as ciências da educação (Scheibe; Daniel, 2002).

As condições objetivas de produção do conhecimento, àquela época muito mais voltado ao tecnicismo educacional, no entanto, fez com que, paulatinamente, a cada nova frustração dos professores que defendiam uma sólida formação teórica para os futuros educadores, tais disciplinas, quando criadas, fossem alocadas nos departamentos de suas áreas específicas. Desse modo, Filosofia da Educação, por exemplo, formava ao lado das várias subdivisões da Filosofia, no Departamento de Filosofia. E, assim, sucessivamente, História da Educação, no Departamento de História; Psicologia da Educação, no Departamento de Psicologia, situação que só foi mudando, vagarosamente, no caso da UFSC, a partir das lutas dos movimentos pela formação de professores, encampadas pelas entidades representativas dos educadores, como a Associação Nacional pela Formação dos Profissionais da Educação (ANFOPE), Associação Nacional de Política e Administração da Educação (ANPAE); Associação Nacional de Pós-Graduação e Pesquisa em Educação (ANPED); Fórum Nacional de Diretores de Faculdades, Centros de Educação ou Equivalentes das Universidades Públicas Brasileiras (FORUMDIR); entre outras, cada qual surgida a seu tempo e movida por correlação de forças específicas de seus momentos históricos.

Faz alguns anos apenas que a disciplina Filosofia da Educação foi devolvida ao Centro de Ciências da Educação, acolhida pelo EED. As demais, no entanto, continuam até o presente nos departamentos originais, isto é, no Departamento de História, de Psicologia, de Sociologia. Esta é uma situação que o CED/UFSC ainda não logrou resolver completamente, embora tenha encontrado outras formas para incorpo-

Educação \& Realidade, Porto Alegre, v. 41, n. especial, p. 1507-1522, dez. 2016. 1513 
rar esses conteúdos sobre educação em disciplinas com nomes alternativos. Citamos como exemplo as disciplinas: Pensamento Pedagógico Brasileiro I e II, de responsabilidade do EED, que tratam das ideias pedagógicas ao longo do tempo no país, compondo, ou, às vezes, fazendo frente à História da Educação I e II, que é ministrada pelo Departamento de História, do Centro de Filosofia e Ciências Humanas (CFH). Outro bom exemplo dessas mudanças é o fato de a disciplina de Sociologia da Educação, lotada no Departamento de Sociologia e Antropologia do CFH, ser destinada ao Curso de Ciências Sociais, mas não ao Curso de Pedagogia, que tem sua própria visão de quais sejam os conteúdos importantes dessa área para a formação de educadores. Dessa discussão, nasceu a disciplina Educação e Sociedade, que trata do pensamento sociológico contemporâneo e sua relação com a educação, vinculada ao EED, assim como também a disciplina chamada de Educação e Trabalho. Já os conteúdos relacionados à Filosofia da Educação recebem no EED o nome de Fundamentos Filosóficos da Educação. A disciplina Psicologia da Educação está alocada no Departamento de Psicologia, no CFH, mas, no CED/UFSC, tratamos de Aprendizagem e Desenvolvimento, disciplina que está alocada no MEN.

Todas essas novas nomenclaturas, mais do que simples mudança de nome ou de locus das disciplinas refletem um movimento importante de valorização da teoria educacional na formação do pedagogo e dos professores em geral, liderado pelas entidades educacionais nascentes no pós-ditadura, mas é, também, fruto do grande esforço empreendido pelo CED/UFSC, já a partir da década de 1970, e mais forte nos anos de 1980 em diante, de propiciar condições de formação em nível de pós-graduação para seus próprios quadros. Nesta empreitada, muitos de nossos professores no início dos anos 1970 foram alunos da Universidade Federal do Rio Grande do Sul, particularmente do seu, à época, recém-criado Programa de Mestrado em Educação. A relação de parceria FACED/UFRGS e CED/UFSC vem desde esse importante momento da vida de ambas as instituições. Mais tarde, já na década de 2000 até o presente, muitos de nós fizemos nossos doutorados na vizinha e companheira de lutas por educação pública e de qualidade, a FACED/UFRGS, mudando um pouco a rota do Norte para o Sul do país.

\section{O CED cria seu Programa de Pós-Graduação em Educação}

Ciente de seu compromisso em formar os professores para além da graduação, uma vez que havia muita demanda das redes municipais e estadual na formação de seus professores, o CED/UFSC começou a oferecer seus primeiros cursos de especialização e aperfeiçoamento (PG lato sensu) na década de 1970, especificamente em 1974. Eram cursos oferecidos gratuitamente aos professores e educadores, tanto nas dependências do CED/UFSC como em outros municípios do estado, constituindo-se em formação continuada para esses profissionais. Des-

1514 Educação \& Realidade, Porto Alegre, v. 41, n. especial, p. 1507-1522, dez. 2016. 
ta experiência, muito bem-sucedida, foram criadas as condições para se sonhar com a criação de um mestrado em educação, pois essa era uma forte demanda de nossos próprios quadros, como também das instituições de ensino superior que começavam a se estabelecer nas cidades de maior porte do interior de Santa Catarina, as chamadas fundações comunitárias de ensino superior.

Assim, dez anos e muitas lutas depois, em 1984, o Centro de Ciências da Educação logra criar seu próprio curso de mestrado. Inicialmente seu quadro local era pequeno, formado pelos primeiros professores da casa que haviam terminado seus doutorados no país ou no exterior. Contava, porém, com a disponibilidade de professores de outras instituições do país, que vinham aos finais de semana preencher algumas de nossas necessidades na oferta das disciplinas consideradas obrigatórias aos perfis de professores que queríamos formar em nível de Pós-Graduação. Não podiam ser negligenciados os conteúdos que nos ajudariam a compreender o funcionamento da sociedade naqueles anos de efervescência política no país, que voltava a pensar em democracia e justiça social, os anos 1980. Não foi fortuito que o foco do curso visava ao estudo das relações entre educação e trabalho numa perspectiva crítica.

No prazo de uma década, com determinação e muito investimento em formação de seus próprios quadros ao longo dos anos 1980 e início dos anos 1990, o CED/UFSC conseguiu aprovar seu primeiro curso em nível de doutorado, em 1994, na linha de Educação e Ciências. Instalou-se, a partir de então, um Programa de Pós-Graduação que viria ser fundamental na formação de professores para as universidades catarinenses, inclusive para nossa coirmã, UDESC. Hoje são estas duas universidades públicas as maiores responsáveis pela formação de quadros capazes de sustentar o ensino e a pesquisa educacional nas várias instituições de ensino superior no estado de Santa Catarina, possibilitando inclusive que as instituições comunitárias, que formam a Associação Catarinense de Fundações de Ensino Superior (ACAFE), tenham hoje professores que dão conta de seus próprios cursos de mestrado, tendo uma delas já instituído seu próprio Programas de Pós-Graduação em Educação que oferece curso de doutorado.

O CED/UFSC cumpriu com excelência seu papel de formador de formadores no âmbito do Estado de Santa Catarina, não deixando também de receber e de formar muitos colegas oriundos de vários outros estados da federação, com ênfase especial aos vizinhos do interior do Estado do Rio Grande do Sul e do Paraná, dividindo tal responsabilidade com as universidades dos respectivos estados.

O Programa de Pós-Graduação do Centro de Ciências da Educação da UFSC (PPGE), atualmente organiza-se em torno de sete linhas de pesquisa efetivamente consolidadas e atende a um número crescente de estudantes em entradas anuais tanto para o mestrado quanto para o doutorado. O CED/UFSC colabora também com o Programa de Pós-

Educação \& Realidade, Porto Alegre, v. 41, n. especial, p. 1507-1522, dez. 2016.1515 
-Graduação em Educação Científica e Tecnológica, aprovado em 2001 pela CAPES, momento em que esta, que era uma das linhas de pesquisa do próprio PPGE, optou por se tornar um programa independente. Hoje ambos os programas são reconhecidos nacional e internacionalmente por sua qualidade e importância na formação de quadros para as instituições de ensino superior de Santa Catarina e do país.

Em menos de quatro décadas, contando ainda com a presença, entre seus quadros, de professores que iniciaram suas carreiras docentes naquela época, o CED/UFSC pode ser considerado um centro irradiador de pesquisas e de formação de pessoal altamente capacitado para responder às novas demandas de mais professores para as instituições de ensino superior que se instalam em Santa Catarina e nas mais distantes localidades do país. Foi, portanto, enfrentado pelo CED/UFSC nesses seus quase cinquenta anos de existência um dos grandes desafios colocados para as faculdades/centros de educação: o de desenvolver cada vez mais o campo científico e acadêmico da área e, ao mesmo tempo, formar bons profissionais para a educação.

Considerando o contexto social cada dia mais complexo e em permanente transformação do mundo, especialmente do Brasil contemporâneo, marcado pela exigência da universalização da educação básica por meio da expansão escolar, exige-se da formação dos profissionais da educação, além de sua inserção nos avanços alcançados pelas teorias educacionais, também o desenvolvimento de uma consciência política do seu trabalho. É parte de sua formação entender que é preciso fazer de sua prática uma verdadeira práxis no desenvolvimento de uma cidadania consciente, crítica e atuante em seus alunos.

Nesse sentido, em sua trajetória, não sem grandes embates e muita luta coletiva, o CED/UFSC conseguiu fazer sua opção pela permanente busca da democratização do acesso da maioria da população brasileira a todos os níveis de escolarização. Defendeu com intransigência o direito de todos a uma educação pública de qualidade, participando ele próprio, por meio de seus professores, engajados que éramos, das grandes discussões que mobilizaram o país nos anos pós-ditadura. Assim, fomos também os escritores coletivos da Nova Carta Constitucional de 1988 no que dizia respeito à educação e, depois, da Lei 9.394, de 1996 (Brasil, 1996), a LDB que pudemos ter. Fomos também os que resistimos ao desmonte neoliberal dos anos de 1990, e os que ajudamos a discutir no país e a reescrever as Resoluções e as normativas que deram corpo às Diretrizes Curriculares para a formação de professores da educação básica de antes e de agora. Todas essas grandes mobilizações foram possíveis pela volta da democracia e também pela organização dos educadores em torno das várias associações que criáramos naqueles anos.

O CED/UFSC, juntamente com a FACED/UFRGS e demais congêneres das outras universidades do país teve importante papel na mobilização nacional do setor da educação, ressignificando, na década de 
1990, o FORUMDIR ${ }^{9}$, que, ao longo de sua existência até os dias de hoje, tem importante atuação na discussão e proposição de políticas públicas para a educação brasileira.

\section{Para Além das Salas de Aula, a Luta pela Redemocratização da Universidade e do País}

O CED/UFSC participou ativamente das lutas pela redemocratização da universidade, nos anos de 1980, embalado pelas possibilidades que se abriam para uma ampla democratização da sociedade brasileira. Assim, no âmbito da UFSC, participamos ativamente do movimento que inventou as eleições para os cargos de direção da universidade - das chefias de departamento aos postos mais altos da hierarquia universitária ainda antes de a legislação as legitimar.

Assim, em 1980, num rompante de autonomia, escolhemos por voto paritário das três categorias que fazem a universidade: docentes, servidores técnicos e estudantes, nossa primeira direção de Centro, elegendo os professores Valpi Costa e Alzira Dutra, ambos do MEN, respectivamente, diretor e vice-diretora. Depois desta conquista, ousamos mais alto e conseguimos, daí em luta conjunta com toda a universidade, participar das eleições para a escolha do reitor, em 1984.

Estávamos ensaiando a construção de um período democrático no Brasil. E como era mobilizadora essa sensação de que poderíamos mudar tudo na vida política da nação! Ávidos por participação, depois de longos anos de ditadura, encharcamo-nos de movimentos pela democracia em todos os níveis. Foi o tempo das eleições para governadores de estados e o rico momento das Diretas Já!, que eletrizaram o país na busca de seu direito máximo: eleger a presidência da República. Eram sólidas, porém, as forças que dominavam os esquemas políticos que mantinham o status quo. Nem por isso desistíamos. Foram muito criativas e formadoras de novas consciências as campanhas que se sucederam no país, na UFSC e no CED/UFSC, exigindo eleições para todos os cargos. No Brasil, a eleição para presidente foi em 1989, mas apenas em 1991 elegemos um Reitor um pouco menos alinhado com as sucessivas administrações da UFSC. Era o grupo que se intitulava: Repensar para Mudar, cujo trabalho articulava-se com o de várias outras reitorias também eleitas pelas respectivas comunidades acadêmicas, num movimento revelador da mudança por que passava o país. UFSC e UFRGS faziam parte dessa nova constelação de poder universitário, bem como outras instituições federais de ensino superior espalhadas pelo Brasil a fora. Foram anos de grande convívio com nossas congêneres, cada qual tentando contribuir para a discussão coletiva dos grandes problemas educacionais deixados pela ditadura, ao mesmo tempo em que desejavam contribuir para sua solução.

Foi nessa época que UFSC e UFRGS, sob a liderança de seus Pró-Reitores de Ensino ${ }^{10}$, encararam a necessidade de conhecer melhor as

Educação \& Realidade, Porto Alegre, v. 41, n. especial, p. 1507-1522, dez. 2016. 1517 
condições de acesso e de permanência dos estudantes das várias áreas nas universidades públicas brasileiras. Era grande o descontentamento reinante e enorme a evasão, constatou-se através de uma pesquisa realizada pelas duas universidades nos anos de 1992 -1996. Estreitaram-se a tal ponto os laços de trabalho entre a UFSC e a UFRGS, que os anos subsequentes foram de muitos projetos e parcerias.

Em 1996, houve mudanças nas reitorias, mas as novas direções da FACED/UFRGS e do CED/UFSC ${ }^{11}$ eleitas no bojo daquele processo de renovação, mantiveram as posições progressistas já alcançadas, dando continuidade aos trabalhos conjuntos. Buscavam, por meio dessa articulação aprofundar as relações democráticas e a participação de todos nas lides da universidade, visando interferir nacionalmente na elaboração de políticas públicas para o setor da educação consentâneas com o projeto de nação que defendíamos. Foi nesta época que o FORUMDIR reassumiu seu protagonismo, sendo sua coordenação assumida fortemente pelos dirigentes das Faculdades/Centros de Educação das IES públicas que entenderam seu papel político na defesa de uma Educação Pública, gratuita e de qualidade, mas, principalmente, sua responsabilidade na discussão e proposição de novas diretrizes para a formação dos professores que tal educação estaria a exigir.

Ao mesmo tempo, reforçávamos as entidades nacionais representativas dos educadores e por meio delas fazíamos intervenções organizadas nos grandes momentos de redemocratização do país e de discussão sobre a educação que queríamos. Ficavam cada dia, mais fortes e diversas as associações que congregavam os educadores: ANFOPE, ANPED, e ANPAE, entre outras. Em todas havia sempre uma ativa presença de professores do CED/UFSC.

Nos anos que se iniciaram em 2003 e chegaram até o presente, sob o governo democrático-popular da era Lula e Dilma, nossos Centros e Faculdades de Educação redobraram suas intervenções na elaboração de políticas públicas para o setor educacional. Fomos grandes parceiros do Ministério da Educação quando se tratava de colaborar com o avanço das propostas que concretamente faziam a educação do país dar conta de democratizar o acesso e de ajudar na permanência dos estudantes em todos os níveis de escolaridade, com ênfase ao ensino superior e à formação de quadros para a escola brasileira. Não poupamos, porém, as necessárias críticas às intervenções que julgávamos ou inadequadas ao projeto que defendíamos, ou muito lentas, frente a tudo que precisávamos fazer. Participamos ativamente das duas Conferências Nacionais de Educação (CONAE), em 2010 e em 2014. Colaboramos na discussão e elaboração de muitas resoluções e leis que fizeram a diferença na condução das políticas educacionais, entre as quais o Plano Nacional de Educação, Lei no 13.005 (Brasil, 2014).

O que nos aguarda nos tempos sombrios que caíram sobre a nação neste ano de 2016, que ficará conhecido como ano do Golpe de Estado civil, midiático e parlamentar, ainda não temos condições de avaliar, 
mas sabemos, pelas experiências da história, que teremos novas e importantes lutas por travar, dessa feita para garantir direitos já conquistados durante os últimos anos, enquanto reunimos forças para ampliá-los e consolidá-los. Em 2019, a Universidade Federal de Santa Catarina estará comemorando os 50 anos do CED/UFSC - esperamos ter o que festejar, nesta trajetória que reúne tantas e importantes conquistas.

Recebido em 26 de agosto de 2016 Aprovado em 22 de outubro de 2016

\section{Notas}

1 Decretos-leis têm força de lei e foram expedidos por Presidentes da República em dois períodos: de 1937 a 1946, e de 1965 a 1989. Nossa atual Constituição não prevê essa possibilidade. Alguns Decretos-Leis ainda permanecem em vigor. Disponível em: <http://www4.planalto.gov.br/legislacao/legislacao-1/ decretos-leis\#content>. Acesso em: 04 out. 2016.

2 O Instituto de Educação de Florianópolis, em 1947, passou a ser denominado de Instituto de Educação e, em 1956, de Colégio Estadual Dias Velho. Em 1964, mudou para Instituto Estadual de Educação, nome que conserva até os dias de hoje. Ver Nascimento e Daniel (2002).

3 A Revista de Educação, publicada nos anos de 1936 e 1937 pelo Estado de Santa Catarina, e a revista Estudos Educacionais, de autoria do Instituto de Educação de Florianópolis, criada para ser lócus de discussão entre alunos, docentes e intelectuais da educação, são publicações que merecem destaque.

4 João Roberto Moreira foi um dos importantes intelectuais que circulava neste espaço. Foi diretor da revista, configurando-se posteriormente como uma personalidade marcante no cenário da educação brasileira, com atuação no Instituto Nacional de Estudos Pedagógicos (INEP), no Centro Latino Americano de Pesquisas em Ciências Sociais (CLAPCS) e no Centro Brasileiro de Pesquisas Educacionais (CBPE). Foi diretor do Grupo Escolar Conselheiro Mafra, em Joinville (SC), nos anos de 1934 e 1935. Foi professor do Curso Normal do Instituto de Educação de Florianópolis, de 1937 a 1943, instituição a qual dirigiu entre 1941 e 1943. Sua aproximação aos princípios da Escola Nova, assim como à Sociologia, aconteceu especialmente nos anos vividos no Paraná, onde participou de grupos intelectuais e assumiu cargos na área da educação, ver Daniel (2009).

5 O Professor Henrique da Silva Fontes, considerado o fundador da Faculdade Catarinense de Filosofia, defendia a criação de uma faculdade de Filosofia em Santa Catarina como algo urgente, porque esta, com seu curso de Pedagogia, viria a completar o aparelhamento do ensino primário catarinense, fornecendo docentes preparados para as escolas de formação de professores, ver Fontes (1960).

6 O Modelo de formação chamado de três mais um, existente até nossos dias, é aquele em que os cursos de licenciatura oferecem aos futuros professores três anos de estudos dos conteúdos específicos de uma dada disciplina escolar, seguidos de mais um ano, em que serão trabalhados os conhecimentos relacionados às ciências da educação e realizados os respectivos estágios supervisionados de docência. Ou seja: em um ano, o estudante de licenciatura por este modelo deverá aprender o difícil ofício de ensinar. Registre-se, entretanto, o

Educação \& Realidade, Porto Alegre, v. 41, n. especial, p. 1507-1522, dez. 2016. 1519 
esforço empreendido pelas Diretrizes Curriculares Nacionais para a Formação de Professores (Parecer CP n. 009, ver Brasil, 2001), substituídas recentemente pela Resolução CNE n. 2 (Brasil, 2015), ambas visando mudar esta realidade e determinar outro percurso curricular e formativo.

7 Inicialmente o CED/UFSC era chamado de Centro de Educação. Seu nome foi mudado para Centro de Ciências da Educação apenas em 1979. Neste ano, por decisão da Administração da UFSC, o atual Departamento de Ciências da Informação, na época denominado de Departamento de Biblioteconomia e documentação - BDC, foi incorporado ao CED/UFSC. Hoje oferece os cursos de Biblioteconomia e Arquivologia, além de uma promissor Programa de Pós-Graduação na área.

8 Com base em nossas memórias, pois não conseguimos encontrar dados oficiais, fizemos uma lista dos nomes dos diretores do CED ao longo de sua existência. As datas dos mandatos mais antigos são apenas aproximadas pelo mesmo motivo, e também porque naquela época, os diretores eram nomeados e seus mandatos seguiam ao sabor das questões internas das administrações. Em ordem cronológica, são os seguintes os/as dirigentes que ocuparam os cargos máximos do CED: 1969 - Nilson Paulo, 1973-Edio Chagas, 1976-Antonio Cesar Becker, 1979 - Carlos Souza, 1980 - Valpi Costa (eleito, assim como todos os que se seguem), 1984 - Alzira Hessmann Dutra, 1988 - Valpi Costa e Francisco Chagas, 1992 - Leda Scheibe, 1996 - 2003 Vera Lúcia Bazzo, 2003-2007 - Carlos Alberto Marques, 2008 Wilson Schmitd, 2011 - Vera Lúcia Bazzo (Pró Tempore), 2012 -2016 Nestor Habkost.

9 Em 1996, por ocasião do VIII ENDIPE, realizado na UFSC, uma grande presença de diretores e diretoras de Faculdades e de Centros de Educação possibilitou o ressurgimento do FORUMDIR, que há tempos estava sem mobilização. Era Diretora do CED/UFSC nessa época a Professora Leda Scheibe, a qual foi eleita sua presidente.

10 Era Pró-Reitor de Ensino da UFSC o Professor Dilvo I. Ristoff; e Pró-Reitora da UFRGS, a Professora Merion Campos Bordas.

11 Professora Vera Lúcia Bazzo - Diretora do CED/UFSC; Professora Merion Campos Bordas - Diretora da FACED/UFRGS.

\section{Referências}

BRASIL. Decreto-Lei no 8.530, de 2 de janeiro de 1946a. Lei Orgânica do Ensino Normal. Diário Oficial [da República Federativa do Brasil], Rio de Janeiro, 4 jan. 1946. Seção I. P. 116.

BRASIL. Decreto-Lei no 9.053, de 12 de março de 1946b. Cria um ginásio de aplicação nas Faculdades de Filosofia do País. Diário Oficial [da República Federativa do Brasil], Rio de Janeiro, 15 mar. 1946. Seção I. P. 3749.

BRASIL. Congresso Nacional. Lei no 5.540, de 28 de novembro de 1968. Fixa normas de organização e funcionamento do ensino superior e sua articulação com a escola média e dá outras providências. Diário Oficial [da República Federativa do Brasil], Brasília, DF, 29 nov. 1968. Seção I. P. 10369.

BRASIL. Lei no 13.005, de 25 de junho de 2014. Aprova o Plano Nacional de Educação - PNE e dá outras providências. Diário Oficial [da República Federativa do Brasil], Brasília, DF, 26 jun. 2014. Edição Extra. P. 1. 
BRASIL. Ministério da Educação. Parecer CNE/CP no 9/2001. Brasília, 2001. Diário Oficial [da República Federativa do Brasil], Brasília, DF, 18 jan. 2001. Disponível em: < http://portal.mec.gov.br/cne/arquivos/pdf/009.pdf>. Acesso em: 4 out. 2016.

BRASIL. Ministério da Educação. Resolução CNE/CP 2/2015, de 1 de julho de 2015. Define as Diretrizes Curriculares Nacionais para a formação inicial em nível superior (cursos de licenciatura, cursos de formação pedagógica para graduados e cursos de segunda licenciatura) e para a formação continuada. Diário Oficial [da República Federativa do Brasil], Brasília, DF, 2 jul. 2015. Seção I. P. 8-12. Disponível em: < http://pronacampo.mec.gov.br/images/pdf/res_cne_ cp_02_03072015.pdf>. Acesso em: 4 out. 2016.

BRASIL. Presidência da República. Lei no 9.394, de 20 de dezembro de 1996. Estabelece as Diretrizes e Bases da Educação Nacional. Diário Oficial [da República Federativa do Brasil], Brasília, DF, 23 dez. 1996. P. 27833.

PERSPECTIVA. Publicação Bianual do Centro de Ciências da Educação - 20142015. Florianópolis, UFSC, n. 1, 2015.

DANIEL, Leziany Silveira. João Roberto Moreira e o Movimento pela Escola Nova em Santa Catarina (1934-1943). Linhas, Florianópolis, UDESC, v. 10, n. 2, p. 181-207, jul./dez. 2009.

DAROS, Maria das Dores. A sociologia na formação dos professores catarinenses nos anos de 1930 e 1940. In: SCHEIBE, Leda; DAROS, Maria das Dores. Formação de Professores em Santa Catarina. Florianópolis: NUP/CED, 2002. P. 34-52.

FONTES, Henrique da Silva. Pensamentos, Palavras e Obras. Primeiro Caderno da Faculdade de Filosofia. Florianópolis: Edição do Autor, 1960.

NASCIMENTO, Carla D’Lourdes do; DANIEL, Leziany Silveira. Instituto de Educação de Florianópolis e os intelectuais catarinenses na década de 40. In: SCHEIBE, Leda; DAROS, Maria das Dores. Formação de Professores em Santa Catarina. Florianópolis: NUP/CED, 2002. P. 53-70.

NECKEL, Roselane; KÜCHLER, Alita Diana (Org.). UFSC 50 anos: trajetórias e desafios. Florianópolis: UFSC, 2010.

SCHEIBE, Leda. O Projeto de Profissionalização docente no contexto da reforma educacional iniciada nos anos 90. Educar em Revista, Curitiba, UFPR, n. 24, p. 177-193, 2004

SCHEIBE, Leda; BAZZO, Vera Lúcia. O papel das faculdades de educação no desenvolvimento do conhecimento educacional e na formação dos profissionais para o magistério. In: TEIVE, Gladys Mary Ghizoni; SCHEIBE, Leda; KOCH, Zenir Maria (Org.). FAED/UDES: 50 anos de educação (1963-2013). Florianópolis: UDESC, 2014.

SCHEIBE, Leda; DANIEL, Leziany Silveira. Formação docente para a Educação Básica: um desafio para o Ensino Superior no século XXI. In: SCHEIBE, Leda; DAROS, Maria das Dores. Formação de Professores em Santa Catarina. Florianópolis: NUP/CED, 2002. P. 11-35.

TANURI, Leonor Maria. História da formação de professores. Revista Brasileira da Educação, São Paulo, ANPEd, n. 14, p. 61-88, maio/ago. 2000. 
Leda Scheibe é professora Emérita da Universidade Federal de Santa Catarina-UFSC. Doutora em Educação pela PUC/SP. Foi presidente da ANFOPE, do FORUMDIR e membro da diretoria da ANPEd em quatro gestões. Participa do corpo docente do Mestrado em Educação da Universidade do Oeste de Santa Catarina e da diretoria da ANPAe.

E-mail: lscheibe@uol.com.br

Vera Lúcia Bazzo é professora da Universidade Federal de Santa Catarina-UFSC, lotada no Centro de Ciências da Educação-CED, no Departamento de Metodologia de Ensino-MEN. Professora Associada nível 4, formada em Letras pela UFSC, mestra em Língua e Literatura Inglesa, pela mesma universidade, e doutora em Educação pela Universidade Federal do Rio Grande do Sul.

E-mail:vbazzo@ced.ufsc.br 